\title{
Clinical Significance of Preoperative Hepatocellular Carcinoma With High Lens culinaris Agglutinin-reactive Fraction of Alpha- Fetoprotein, But Low Alpha-Fetoprotein
}

\author{
TAKANOBU YAMAO, YO-ICHI YAMASHITA, KATSUNORI IMAI, NAOKI UMEZAKI, MASAYO TSUKAMOTO, \\ YUKI KITANO, KOTA ARIMA, TATSUNORI MIYATA, SHIGEKI NAKAGAWA, HIROHISA OKABE, \\ HIROMITSU HAYASHI, AKIRA CHIKAMOTO, TAKATOSHI ISHIKO and HIDEO BABA \\ Department of Gastroenterological Surgery, Graduate School of Life Sciences, \\ Kumamoto University, Kumamoto, Japan
}

\begin{abstract}
Background: The aim of this study was to verify the significance of high Lens culinaris agglutinin-reactive fraction of $\alpha$-fetoprotein (AFP-L3) in patients with hepatocellular carcinoma (HCC) with low AFP. Materials and Methods: There were 283 patients with low AFP who underwent initial hepatic resection with or without radiofrequency ablation for HCC. Patients were divided into two groups based on AFP-L3 values: >10\%: high AFP-L3 $(n=24)$; and $\leq 10 \%$ : low AFP-L3 $(n=259)$. Overall survival $(O S)$ and 2-year recurrence rates were compared, and independent prognostic factors were identified. Results: The $O S$ and 2-year recurrence rates of the high AFP-L3 group were significantly worse than those of the low AFP-L3 group. The independent prognostic factors for poor $O S$ were des-gamma-carboxy prothrombin (DCP) of $>40 \mathrm{mAU} / \mathrm{ml}$, microvascular invasion, and invasive growth, and those for 2-year recurrence were ${ }^{99 m}$ Tc-galactosyl human serum albumin uptake ratio of $<0.90, D C P$ of $>40 \mathrm{mAU} / \mathrm{ml}$, multiple tumors, microvascular invasion, and poor differentiation. DCP levels increased with AFP-L3, and cases with high DCP and AFP-L3 had worse prognoses and higher 2-year recurrence rates compared to those with elevation of only one of these. Conclusion: Patients with high AFP-L3 but low AFP have poor prognosis and high 2-year recurrence rates. DCP strongly reflects $H C C$ malignancy in patients with low AFP.
\end{abstract}

Correspondence to: Yo-ichi Yamashita, MD, Ph.D., F.A.C.S., Kumamoto, 1-1-1, Chuo-ku, Honjo, Kumamoto 860-8556, Japan. Tel: +81 963735211, Fax: +81 963714378, e-mail: y-yama@kumamotou.ac.jp

Key Words: Hepatocellular carcinoma, Lens culinaris agglutininreactive fraction of alpha-fetoprotein, hepatic resection, radiofrequency ablation.
Hepatocellular carcinoma (HCC) is the fifth most common malignancy and the second leading cause of cancer-related deaths worldwide (1). Since in most patients with HCC the disease is asymptomatic, early diagnosis and treatment are necessary for cure. For early and accurate diagnosis, tumor markers, such alpha-fetoprotein (AFP), des-gamma-carboxy prothrombin (DCP), and Lens culinaris agglutinin-reactive fraction of AFP (AFP-L3), are useful in daily clinical practice (2-6). AFP has one sugar chain per molecule, and it can be divided into the L. culinaris agglutin non-binding fraction (L1), the weakly binding fraction (L2), and binding fraction (L3) (2). AFP-L3 is detected mainly in patients with HCC, and L1 is usually expressed in patients with chronic hepatitis and liver cirrhosis (2). AFP-L3 was introduced as a potentially more specific marker for HCC than AFP, but its use is limited by low sensitivity $(4,6)$. Elevated AFP levels have been observed in patients with cirrhosis or exacerbation of chronic hepatitis (7); therefore, AFP has low specificity for HCC detection. Generally, when the AFP level increases, AFP fractions are measured for HCC diagnosis. However, the clinical significance of the elevation of the AFP-L3 fraction, without AFP elevation, is unclear. Few studies have reported on patients with high AFP-L3 but low AFP (8-10).

Therefore, this study aimed to verify the clinical significance of high AFP-L3 in patients with low AFP who underwent hepatic resection (HR) or radiofrequency ablation (RFA) for HCC.

\section{Materials and Methods}

Patients. A retrospective cohort study was performed from January 2005 to December 2015 at the Kumamoto University Hospital (Kumamoto, Japan). Informed consent was obtained from all patients before treatments according to the provisions of the Declaration of Helsinki. This study was approved by the Ethical Committee of our Institute and was registered with the Committee (numbers 1084 and 1274). 
Table I. Comparisons of the patient backgrounds, and tumor-related and surgical factors.

\begin{tabular}{|c|c|c|c|c|}
\hline & & \multicolumn{2}{|c|}{ AFP-L3 } & \multirow[t]{2}{*}{$p$-Value } \\
\hline & & High $(>10 \%) n=24$ & Low $(\leq 10 \%) \mathrm{n}=259$ & \\
\hline Age, years & Median (range) & $71.5(49-82)$ & $69(38-88)$ & 0.69 \\
\hline \multirow[t]{2}{*}{ Gender, $\mathrm{n}$} & Male & 17 & 204 & 0.44 \\
\hline & Female & 7 & 55 & \\
\hline HBs-Ag positive, $\mathrm{n}$ & HBs-Ag positive, $n$ & 6 & 48 & 0.42 \\
\hline HCV-Ab positive, $\mathrm{n}$ & $\mathrm{HCV}-\mathrm{Ab}$ positive, $\mathrm{n}$ & 14 & 134 & 0.67 \\
\hline Platelet count, $\times 10^{4} / \mu \mathrm{l}$ & Median (range) & $13.3(6.9-41.1)$ & $13.8(0-101)$ & 0.17 \\
\hline Albumin, $\mathrm{g} / \mathrm{dl}$ & Median (range) & $3.6(3.2-5.0)$ & $2.5(2.5-5.1)$ & 0.71 \\
\hline Total bilirubin, mg/dl & Median (range) & $0.9(0.6-1.7)$ & $0.8(0.2-3.3)$ & 0.069 \\
\hline Prothrombin activity, $\%$ & Median (range) & $91(76-129)$ & $94(36-140)$ & 0.15 \\
\hline ICG-R15, \% & Median (range) & $12.4(2.0-65.4)$ & $13.1(0-70.9)$ & 0.67 \\
\hline 99mTc-GSA LHL15 & Median (range) & $0.91(0.72-0.97)$ & $0.92(0.62-0.90)$ & 0.73 \\
\hline \multirow[t]{2}{*}{ Child-Pugh class } & A & 24 & 247 & 0.24 \\
\hline & $\mathrm{B}$ & 0 & 12 & \\
\hline $\mathrm{AFP}, \mathrm{ng} / \mathrm{ml}$ & Median (range) & $13.2(1.6-19.6)$ & $5.4(0-19.7)$ & $<0.0001$ \\
\hline $\mathrm{DCP}, \mathrm{mAU} / \mathrm{ml}$ & Median (range) & $139.5(15-95120)$ & $32(0-45663)$ & 0.0047 \\
\hline Tumor size, mm & Median (range) & $27(12-85)$ & $27(2-200)$ & 0.45 \\
\hline Tumor number, $\mathrm{n}$ & Median (range) & $1(1-4)$ & $1(1-8)$ & 0.58 \\
\hline Operative time, $\min$ & Median (range) & $374(42-485)$ & $362(10-774)$ & 0.94 \\
\hline Blood loss, g & Median (range) & $350(5-1207)$ & $290(0-3404)$ & 0.50 \\
\hline Red blood cell transfusion, $\mathrm{n}(\%)$ & & $1(4.2)$ & $15(5.9)$ & 1.0 \\
\hline \multirow[t]{2}{*}{ Major complication, $\mathrm{n}^{*}$} & Yes & 6 & 30 & 0.11 \\
\hline & No & 21 & 178 & \\
\hline \multirow[t]{2}{*}{ MVI } & Yes & 10 & 64 & 0.15 \\
\hline & No & 11 & 140 & \\
\hline \multirow[t]{2}{*}{ Growth pattern, $\mathrm{n}$} & EG & 20 & 197 & 0.33 \\
\hline & IG & 1 & 3 & \\
\hline \multirow[t]{2}{*}{$\mathrm{FC}, \mathrm{n}$} & Yes & 16 & 172 & 0.50 \\
\hline & No & 5 & 30 & \\
\hline \multirow[t]{2}{*}{ FC-inf, $n$} & Yes & 14 & 148 & 0.58 \\
\hline & No & 6 & 37 & \\
\hline \multirow[t]{2}{*}{ Differentiation } & Well, moderate & 4 & 32 & 0.75 \\
\hline & Poor & 17 & 172 & \\
\hline \multirow[t]{3}{*}{ Treatment } & $\mathrm{HR}$ & 21 & 183 & 0.16 \\
\hline & $\mathrm{HR}+\mathrm{RFA}$ & 0 & 23 & \\
\hline & RFA & 3 & 53 & \\
\hline
\end{tabular}

MVI: Microvascular invasion; HBs-Ag: hepatitis B surface antigen; HCV-Ab: anti-hepatitis C antibody; ICG-R15: indocyanine green retention rate at $15 \mathrm{~min}$; $99 \mathrm{~m} \mathrm{Tc}-\mathrm{GSA}$ LHL15: uptake ratio of $99 \mathrm{~m} \mathrm{Tc}$-galactosyl human serum albumin of the liver to that of the liver plus heart at $15 \mathrm{~min}$; AFP: $\alpha$ fetoprotein; AFP-L3: Lens culinaris agglutinin-reactive fraction of AFP; DCP: des- $\gamma$-carboxy prothrombin; EG: expansive growth; IG: invasive growth; FC: capsule formation; FC-inf: cancerous infiltration of the capsule; HR: hepatic resection; RFA: radiofrequency ablation. *Clavien-Dindo grade III-IV.

From a total cohort of 697 consecutive patients who underwent HR, RFA, or HR with RFA for primary HCC, 283 patients with low AFP, i.e. $\leq 20 \mathrm{ng} / \mathrm{ml}$, with an observation period of 2 years or more were enrolled. The 283 patients were divided into high $(>10 \% ; n=24)$ and low ( $\leq 10 \%$; $=259)$ AFP-L3 groups. Of the 283 patients, 204 underwent HR, 56 underwent RFA, and 23 underwent HR with RFA. Serum concentrations of AFP, AFP-L3, and DCP were measured within 2 weeks before surgery. Serum AFP concentrations were measured using a chemiluminescent enzyme immunoassay (COBAS $800{ }^{\circledR}$ AFP-II; Roche Diagnostics Ltd., Indianapolis, IN, USA). Serum AFP-L3 concentrations were determined by lectin affinity electrophoresis coupled with an automated immunoassay system assay ( $\mu$ TASWako i30 ${ }^{\circledR}$; Wako Pure Chemical Industries, Ltd., Osaka,
Japan), and AFP-L3 concentrations were expressed as a percentage of total AFP (AFPL3/total AFP $\times 100$ ). Serum DCP concentrations were determined by chemiluminescent enzyme immunoassays (Lumipulse ${ }^{\circledR}$ PIVKAII-N; Fujirebio Inc., Tokyo, Japan).

Diagnosis. The diagnosis of HCC mainly depends on typical findings, i.e. early-phase enhancement and late-phase washout by at least two imaging techniques such as computed tomography (CT) and magnetic resonance imaging (MRI). Elevation in tumor marker levels, including, those of AFP, AFP-L3, and DCP, are also considered supplemental. Because of the fear for cancer cell seeding, liver biopsy prior to RFA was not performed in our series. 
A

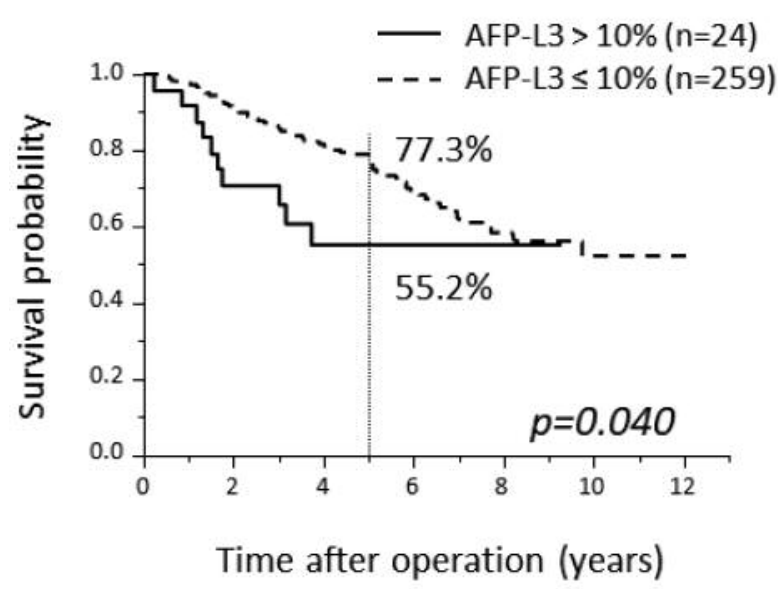

B

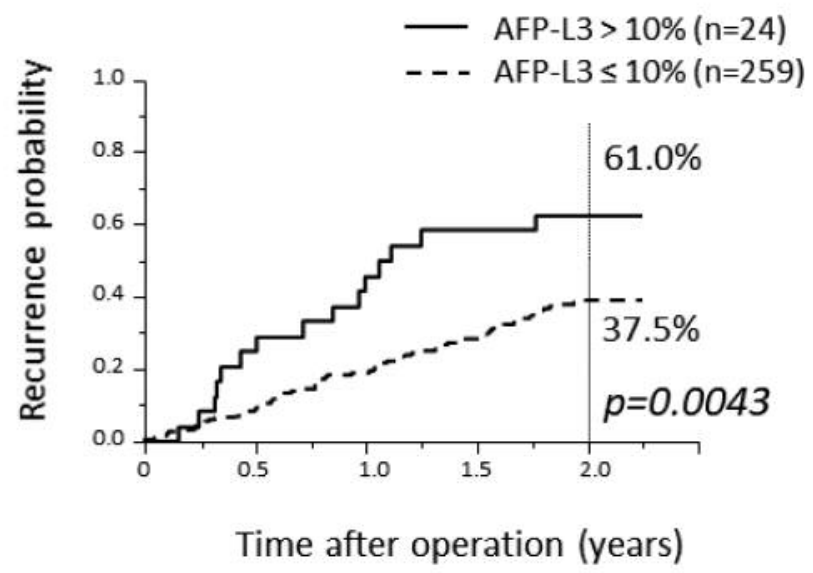

Figure 1. Relationship between Lens culinaris agglutinin-reactive fraction of $\alpha$-fetoprotein (AFP-L3) and overall survival (A) and 2-year recurrence rate $(B)$ using the Kaplan-Meier method.

Treatments and follow-up. The surgical procedure was selected based on tumor location, tumor extent, liver function, and the patient's general condition, as described previously (11). For almost all patients, the treatment plan was discussed at a weekly institutional HCC board. HR was considered the first choice of treatment for patients with HCC with good liver functional reserve (12). The approach of RFA, such as percutaneous, laparoscopic, thoracoscopic, and laparotomy, was considered depending on the HCC location. If a residual tumor existed during the follow-up CT in the week following RFA, an additional RFA was performed $(n=2)$.

Thereafter, all patients were regularly followed-up by imaging modalities, including CT or MRI, and tumor markers such as AFP, AFP-L3, and DCP, every three months (11). When HCC recurrence was detected in the remnant liver, treatments were selected according to the same strategy as previously (13). Postoperative short-and long-term outcomes were evaluated, including mortality, and major complications were graded based on Clavien-Dindo classification III or more (14), peritoneal pleural tumor seeding, and local recurrence.

Statistical analysis. Continuous variables are expressed as the median and range, and were compared using the Mann-Whitney $U$ test. Categorical variables were compared using the chi-square or Fisher's exact tests, as appropriate. Survival curves for overall survival (OS) and 2-year recurrence rates, to check early recurrence, were generated by the Kaplan-Meier method. The log-rank test was used for comparisons. A Cox regression analysis was utilized for the univariate and multivariate analyses of OS and 2-year recurrence rates. All statistical analyses were performed using JMP ${ }^{\circledR}$ (Version 10; SAS Institute, Cary, NC, USA). $p$-Values of less than 0.05 were considered statistically significant.

\section{Results}

Comparisons of clinicopathological factors between the groups with high and low AFP-L3. Comparisons of the background, tumor-related, and surgical factors are summarized in Table I. Based on our Institution's criteria, the AFP-L3 cut-off value was set at $10 \%$. There were no significant differences among patient background factors, such as age, sex, HCC etiology, and liver function, and among pathological and surgical factors. The median AFP value in the group with high AFP-L3 was significantly higher than that with low AFP-L3 (13.1 vs. $5.4 \mathrm{ng} / \mathrm{ml}$, $p<0.0001)$. The median DCP value in the group with high AFP-L3 was also significantly higher than that with low AFP-L3 (139.5 vs. $32 \mathrm{mAU} / \mathrm{mI}, p=0.0047)$.

OS and 2-year recurrence rate. The OS and 2-year recurrence rates curves of the two groups are shown in Figure 1. The OS rates of the group with high AFP-L3 was significantly lower than that with low AFP-L3 (5-year OS rate: $55.2 \%$ vs. $77.3 \%$, $p=0.040$, Figure 1A). Similarly, the 2-year recurrence rates of the group with high AFP-L3 was significantly higher than that of the group with low AFP-L3 (2-year recurrence rate: $61.0 \%$ vs. $37.5 \%, p=0.0043$, Figure 1B).

Prognostic factors for $O S$ and 2-year recurrence. The univariate and multivariate analyses for OS and 2-year recurrence free survival are summarized in Tables II and III. The multivariate analysis revealed that the factors independently associated with poor OS were DCP $>40$ $\mathrm{mAU} / \mathrm{ml}$ [hazard ratio $(\mathrm{HR})=1.84, p=0.021$ ], microvascular invasion (MVI) $(\mathrm{HR}=2.25, p=0.0014)$, and invasive growth type $(\mathrm{HR}=4.22, p=0.048)$ (Table II). The independent factors for 2-year recurrence were uptake ratio of $99 \mathrm{~m}$ Tc-galactosyl human serum albumin of the liver to that of the liver plus heart at $15 \mathrm{~min}<0.90(\mathrm{HR}=2.09, p=0.001), \mathrm{DCp}>40 \mathrm{~mA} / \mathrm{ml}$ $(\mathrm{HR}=1.58, p=0.043)$, multiple tumors $(\mathrm{HR}=2.03, p=0.002)$, and MVI $(\mathrm{HR}=1.98, p=0.0015)$ (Table III). 
Table II. Univariate and multivariate analyses for factors associated with overall survival.

\begin{tabular}{|c|c|c|c|c|c|c|}
\hline & \multicolumn{3}{|c|}{ Univariate } & \multicolumn{3}{|c|}{ Multivariate } \\
\hline & Hazard ratio & $95 \% \mathrm{CI}$ & $p$-Value & Hazard ratio & $95 \% \mathrm{CI}$ & $p$-Value \\
\hline Age $>75$ years & 1.05 & $0.88-2.65$ & 0.13 & & & \\
\hline Male & 1.51 & $0.63-1.85$ & 0.86 & & & \\
\hline HBs-Ag-positive & 0.81 & $0.44-1.40$ & 0.47 & & & \\
\hline HCV-Ab-positive & 1.17 & $0.75-1.83$ & 0.49 & & & \\
\hline Platelet count $<10 \times 10^{4} / \mu 1$ & 1.05 & $0.47-1.32$ & 0.91 & & & \\
\hline Albumin $<3.5 \mathrm{~g} / \mathrm{dl}$ & 1.39 & $0.72-2.47$ & 0.31 & & & \\
\hline Total bilirubin $>1.0 \mathrm{mg} / \mathrm{dl}$ & 0.89 & $0.56-1.57$ & 0.79 & & & \\
\hline Prothrombin activity $<80 \%$ & 0.81 & $0.69-2.37$ & 0.41 & & & \\
\hline ICG-R15 >10\% & 1.49 & $0.96-2.31$ & 0.077 & & & \\
\hline 99mTc-GSA LHL15 <0.90 & 0.93 & $0.57-1.47$ & 0.76 & & & \\
\hline AFP-L3 > 10\% & 1.97 & $0.96-3.65$ & 0.065 & & & \\
\hline $\mathrm{DCP}>40 \mathrm{mAU} / \mathrm{ml}$ & 2.51 & $1.61-4.00$ & $<0.0001$ & 1.84 & $1.09-3.18$ & 0.021 \\
\hline Tumor size $>2 \mathrm{~cm}$ & 1.58 & $0.96-2.75$ & 0.073 & & & \\
\hline Multiple tumors & 1.62 & $1.02-2.52$ & 0.041 & & & \\
\hline Major complication* & 1.58 & $0.86-2.73$ & 0.14 & & & \\
\hline MVI & 2.48 & $1.54-3.99$ & 0.0002 & 2.25 & $1.37-3.71$ & 0.0014 \\
\hline Growth pattern IG & 4.22 & $1.02-11.5$ & 0.047 & 4.22 & $1.02-11.7$ & 0.048 \\
\hline $\mathrm{FC}$ & 1.23 & $0.65-2.66$ & 0.55 & & & \\
\hline FC-inf & 1.43 & $0.96-4.74$ & 0.28 & & & \\
\hline Poor differentiation & 2.01 & $0.87-4.28$ & 0.093 & & & \\
\hline
\end{tabular}

95\% CI: 95\% Confidence interval; MVI: microvascular invasion; HBs-Ag: hepatitis B surface antigen; HCV-Ab: anti-hepatitis C antibody; ICG-

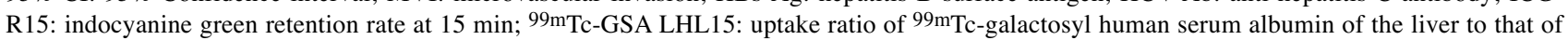
the liver plus heart at $15 \mathrm{~min}$; AFP: $\alpha$-fetoprotein; AFP-L3: Lens culinaris agglutinin-reactive fraction of AFP; DCP: des- $\gamma$-carboxy prothrombin; EG: expansive growth; IG: invasive growth; FC: capsule formation; FC-inf: cancerous infiltration of the capsule. *Clavien-Dindo grade III-IV.

Clinical significance of DCP compared to AFP-L3. Significantly positive correlation was observed between AFP-L3 and DCP $(p<0.0001, \mathrm{R} 2=0.11$, Figure 2$)$.

Table IV shows the relationship between DCP levels and prognostic factors. In the group with high DCP, high AFP-L3 was significantly more frequent $(p=0.0055)$. The presence of MVI and poor differentiation were more frequent in the group with high DCP ( $p=0.0003$ and $p=0.0031$, respectively).

According to qualitative evaluation of these two tumor markers, we classified the HCC cases into four groups based on AFP-L3 and DCP levels. Type I had low AFP-L3 and low DCP $(n=142)$, type II had low AFP-L3 and high DCP $(n=117)$, type III had high AFP-L3 and low DCP $(n=6)$, and type IV had high AFP-L3 and high DCP $(n=18)$ (Figure 3). Both OS and 2-year recurrence rates of patients with type IV were significantly worse than those of any other type. These results suggest that DCP more strongly reflects the degree of malignancy, compared to AFP-L3, in patients with low AFP; however, those with both high DCP and AFP-L3 had worse survival than those with elevation of only one of these markers.

\section{Discussion}

The present study investigated the clinical significance of high AFP-L3, but low AFP in patients who underwent

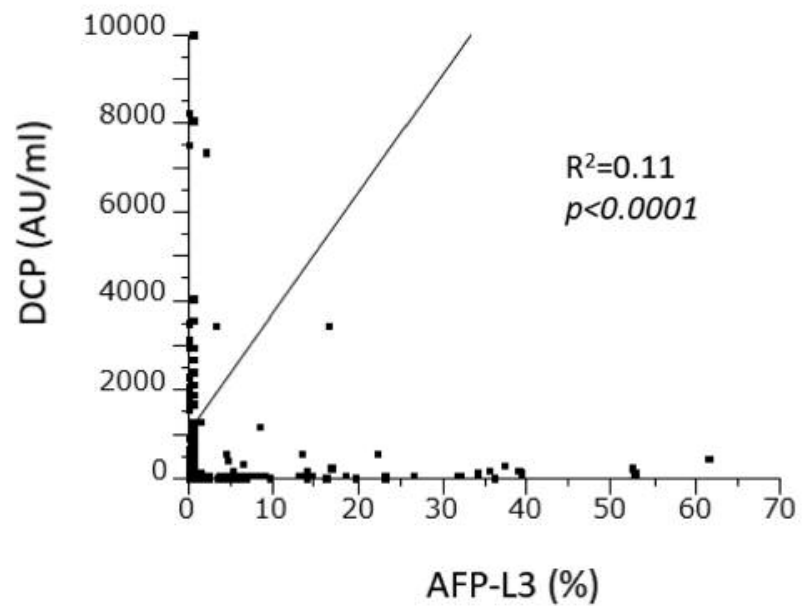

Figure 2. Relationship between Lens culinaris agglutinin-reactive fraction of $\alpha$-fetoprotein (AFP-L3) and des- $\gamma$-carboxy prothrombin $(D C P)$. A positive correlation was observed between AFP-L3 and DCP $\left(p<0.0001, R^{2}=0.11\right)$.

surgical treatment for primary HCC. Our results showed that OS and 2-year recurrence rates of the group with high AFPL3 were significantly worse than those of the group with low AFP-L3. However, AFP-L3 elevation was not an 
A

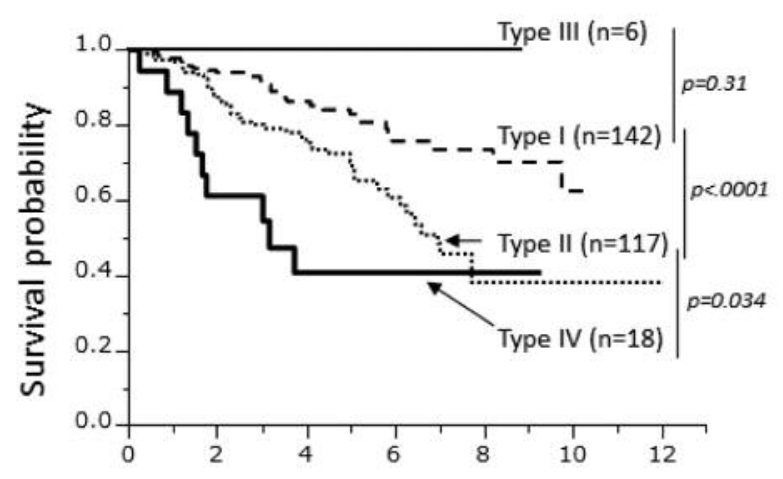

Time after operation (years)
B

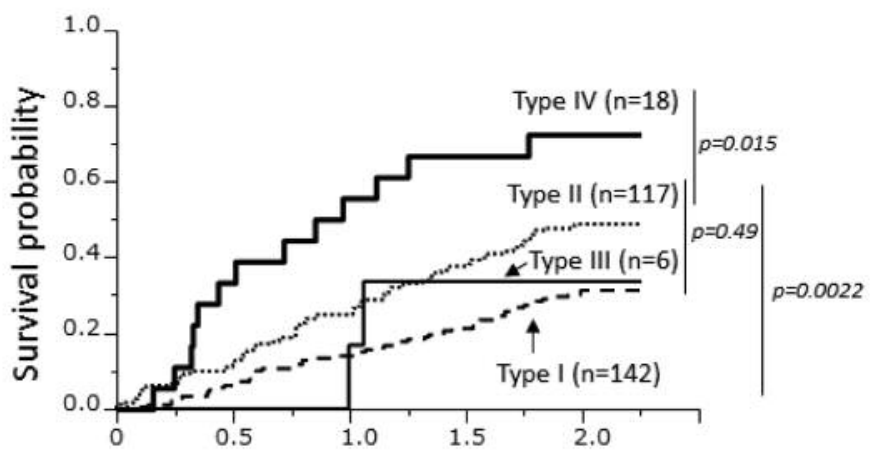

Time after operation (years)

Figure 3. Overall survival (A) and 2-year recurrence $(B)$ according to combined Lens culinaris agglutinin-reactive fraction $\alpha$-fetoprotein (AFP-L3) and des- $\gamma$-carboxy prothrombin $(D C P)$ using the Kaplan-Meier method. Patients were classification into the following groups according to AFPL3 and DCP levels: Type I had low AFP-L3 and low DCP, type II had low AFP-L3 and high DCP, type III had high AFP-L3 and low DCP, and type IV had high AFP-L3 and high DCP.

Table III. Univariate and multivariate analyses of factors associated with 2-year recurrence rates.

\begin{tabular}{|c|c|c|c|c|c|c|}
\hline & \multicolumn{3}{|c|}{ Univariate } & \multicolumn{3}{|c|}{ Multivariate } \\
\hline & Hazard ratio & $95 \% \mathrm{CI}$ & $p$-Value & Hazard ratio & $95 \% \mathrm{CI}$ & $p$-Value \\
\hline Age $>75$ years & 1.14 & $0.69-1.82$ & 0.59 & & & \\
\hline Male & 1.34 & $0.85-2.20$ & 0.21 & & & \\
\hline HBs-Ag-positive & 1.12 & $0.69-1.74$ & 0.63 & & & \\
\hline HCV-Ab-positive & 1.25 & $0.87-1.82$ & 0.23 & & & \\
\hline Platelet count $<10 \times 10^{4} / \mu 1$ & 0.64 & $0.40-1.01$ & 0.053 & & & \\
\hline Albumin $<3.5 \mathrm{~g} / \mathrm{dl}$ & 1.61 & $0.98-2.53$ & 0.060 & & & \\
\hline Total bilirubin $>1.0 \mathrm{mg} / \mathrm{dl}$ & 0.87 & $0.56-1.32$ & 0.53 & & & \\
\hline Prothrombin activity $<80 \%$ & 0.95 & $0.53-1.58$ & 0.85 & & & \\
\hline ICG-R15 >10\% & 1.43 & $0.99-2.06$ & 0.057 & & & \\
\hline 99m Tc-GSA LHL15 <0.90 & 1.54 & $1.06-2.22$ & 0.024 & 2.09 & $1.36-3.18$ & 0.001 \\
\hline AFP-L3 > 10\% & 2.16 & $1.21-3.61$ & 0.013 & & & \\
\hline $\mathrm{DCP}>40 \mathrm{mAU} / \mathrm{ml}$ & 2.02 & $1.40-2.95$ & 0.0001 & 1.58 & $1.02-2.49$ & 0.043 \\
\hline Tumor size $>2 \mathrm{~cm}$ & 2.25 & $1.42-3.74$ & 0.0002 & & & \\
\hline Multiple tumors & 1.90 & $1.29-2.76$ & 0.0013 & 2.03 & $1.30-3.10$ & 0.002 \\
\hline Major complication* & 1.90 & $1.15-3.00$ & 0.013 & & & \\
\hline MVI & 2.21 & $1.54-3.99$ & 0.0002 & 1.98 & $1.30-2.99$ & 0.0015 \\
\hline Growth pattern IG & 3.63 & $1.02-11.5$ & 0.068 & & & \\
\hline $\mathrm{FC}$ & 1.66 & $0.65-2.66$ & 0.10 & & & \\
\hline FC-inf & 1.49 & $0.96-4.74$ & 0.15 & & & \\
\hline Poor differentiation & 1.65 & $1.10-2.52$ & 0.016 & 1.60 & $1.04-2.48$ & 0.031 \\
\hline
\end{tabular}

95\% CI: 95\% Confidence interval; MVI: microvascular invasion; HBs-Ag: hepatitis B surface antigen; HCV-Ab: anti-hepatitis C antibody; ICGR15: indocyanine green retention rate at $15 \mathrm{~min}$; $99 \mathrm{mTc}-\mathrm{GSA}$ LHL15: uptake ratio of 99mTc-galactosyl human serum albumin of the liver to that of the liver plus heart at $15 \mathrm{~min}$; AFP: $\alpha$-fetoprotein; AFP-L3: Lens culinaris agglutinin-reactive fraction of AFP; DCP: des- $\gamma$-carboxy prothrombin; EG: expansive growth; IG: invasive growth; FC: capsule formation; FC-inf: cancerous infiltration of the capsule. *Clavien-Dindo grade III-IV.

independent poor prognostic factor for OS or 2-year recurrence. In contrast, elevation of DCP was an independent prognostic factor for poor OS and 2-year recurrence. Several reports have compared the relationship among AFP, AFP-L3 and, DCP in the prognosis of patients with HCC after HR or RFA (3, 8, 9, 15-18); however, reports on the relationship between high AFL-L3 but low AFP and the prognosis of patients with HCC have been limited (8-10). 
Table IV. The relationships among des- $\gamma$-carboxy prothrombin (DCP), Lens culinaris agglutinin-reactive fraction of $\alpha$-fetoprotein (AFP-L3), and factors associated with early recurrence or poor prognosis.

\begin{tabular}{|c|c|c|c|}
\hline & \multicolumn{2}{|c|}{$\mathrm{DCP}, \mathrm{n}$} & \multirow[b]{2}{*}{$p$-Value } \\
\hline & $\begin{array}{c}>40 \mathrm{mAU} / \mathrm{ml} \\
(\mathrm{n}=135)\end{array}$ & $\begin{array}{c}\leq 40 \mathrm{mAU} / \mathrm{ml} \\
(\mathrm{n}=148)\end{array}$ & \\
\hline \multicolumn{4}{|l|}{ AFP-L3 } \\
\hline$>10 \%$ & 18 & 6 & 0.0055 \\
\hline$\leq 10 \%$ & 117 & 142 & \\
\hline \multicolumn{4}{|l|}{ 99m TcGSA LHL15 } \\
\hline$<0.90$ & 42 & 52 & 0.53 \\
\hline$\geq 0.9$ & 93 & 96 & \\
\hline \multicolumn{4}{|l|}{ Tumor number } \\
\hline Multiple & 30 & 44 & 0.17 \\
\hline Single & 104 & 102 & \\
\hline \multicolumn{4}{|l|}{ MVI } \\
\hline Yes & 53 & 21 & 0.0003 \\
\hline No & 69 & 82 & \\
\hline \multicolumn{4}{|l|}{ Growth pattern } \\
\hline EG & 116 & 101 & 0.63 \\
\hline IG & 3 & 1 & \\
\hline \multicolumn{4}{|l|}{ Differentiation } \\
\hline Well, moderate & 45 & 59 & 0.0031 \\
\hline Poor & 77 & 44 & \\
\hline
\end{tabular}

MVI: Microvascular invasion; 99mTc-GSA LHL15, uptake ratio of $99 \mathrm{~m} \mathrm{Tc}$-galactosyl human serum albumin of the liver to that of the liver plus heart at 15 min; EG, expansive growth; IG, invasive growth.

Nouso et al. reported that high AFP-L3 ( $\geq 10 \%)$, but low AFP in patients with HCC after RFA treatment was an independent factor of poor prognosis (8). Kobayashi et al. also showed a similar result in a total of 110 patients with HCC (9). Toyoda et al. showed the usefulness of the high sensitivity of AFP-L3 for HCC diagnosis in patients with low AFP after HCC treatments (10). In agreement with previous studies, similar results were obtained with regards to the ability of preoperative high AFP-L3 to indicate poor prognosis after surgical treatments in patients with HCC and low AFP. In the present study, DCP, which was an independent factor of prognosis for both poor OS and 2-year recurrence, was also elevated in patients with high AFP-L3. In addition, those with high AFP-L3 and DCP had significantly worse prognoses than those with only one of these. This indicates the clinical usefulness of measuring AFP-L3.

Our results suggested that DCP elevation more strongly reflects malignancy of HCC than does AFP-L3; therefore, the clinical significance of measurement of DCP would be greater than that of AFP-L3 in patients with low AFP levels. To our knowledge, this study may be the first report to show the superiority of DCP measurements compared to AFP-L3 as a prognostic factor for patients with HCC with low AFP levels, particularly focusing on local HR and RFA treatments. As shown in previous reports, high DCP level correlated with the presence of MVI and poor HCC differentiation $(19,20)$; therefore, it is presumed that the malignancy of HCC in patients with low AFP was reflected by DCP elevation. However, in patients using warfarin or vitamin K, DCP increased irrespectively of the presence or absence of HCC (21). As the aging population increases, warfarin usage increases; therefore, the role of DCP gradually will decrease. AFP-L3 will gradually have a greater clinical significance than DCP. It seems that the clinical significance of AFP-L3 measurements is also limited. However, that those with elevation of both AFP-L3 and DCP had significantly worse prognoses than those with only one, demonstrates the merit of measuring AFP-L3 levels in patients with low AFP when measurements of DCP are available.

This study has several limitations. This was a retrospective study from a single institution, and the sample size was relatively small. In addition, the survival results and prognostic factors may change depending on the AFP or AFP-L3 cut-off values used.

In conclusion, in patients with HCC with low AFP, high AFP-L3 may indicate poor prognosis and increased likelihood of 2-year recurrence; however, malignancy of HCC is more strongly reflected by DCP than by AFP-L3. Therefore, the clinical significance of DCP may be higher for patients with HCC with low AFP compared to that of AFP-L3.

\section{Conflicts of Interest}

The Authors declare that they have no conflicts of interest in regard to this study.

\section{References}

1 Ferlay J, Colombet M, Soerjomataram I, Mathers C, Parkin DM, Pineros M, Znaor A and Bray F: Estimating the global cancer incidence and mortality in 2018: Globocan sources and methods. Int J Cancer, 2018. doi: 10.1002/ijc.31937. [Epub ahead of print]

2 Sauzay C, Petit A, Bourgeois AM, Barbare JC, Chauffert B, Galmiche A and Houessinon A: Alpha-foetoprotein (AFP): A multi-purpose marker in hepatocellular carcinoma. Clin Chim Acta 463: 39-44, 2016.

3 Song PP, Xia JF, Inagaki Y, Hasegawa K, Sakamoto Y, Kokudo $\mathrm{N}$ and Tang W: Controversies regarding and perspectives on clinical utility of biomarkers in hepatocellular carcinoma. World J Gastroenterol 22(1): 262-274, 2016.

4 Marrero JA, Feng Z, Wang Y, Nguyen MH, Befeler AS, Roberts LR, Reddy KR, Harnois D, Llovet JM, Normolle D, Dalhgren J, Chia D, Lok AS, Wagner PD, Srivastava S and Schwartz M: Alpha-fetoprotein, des-gamma carboxyprothrombin, and lectinbound alpha-fetoprotein in early hepatocellular carcinoma. Gastroenterology 137(1): 110-118, 2009.

5 Yi X, Yu S and Bao Y: Alpha-fetoprotein-L3 in hepatocellular carcinoma: A meta-analysis. Clin Chim Acta 425: 212-220, 2013. 
6 Lok AS, Sterling RK, Everhart JE, Wright EC, Hoefs JC, Di Bisceglie AM, Morgan TR, Kim HY, Lee WM, Bonkovsky HL and Dienstag JL: Des- $\gamma$-carboxy prothrombin and $\alpha$-fetoprotein as biomarkers for the early detection of hepatocellular carcinoma. Gastroenterology 138(2): 493-502, 2010.

7 Di Bisceglie AM and Hoofnagle JH: Elevations in serum alphafetoprotein levels in patients with chronic hepatitis B. Cancer 64(10): 2117-2120, 1989.

8 Nouso K, Kobayashi Y, Nakamura S, Kobayashi S, Takayama H, Toshimori J, Kuwaki K, Hagihara H, Onishi H, Miyake Y, Ikeda F, Shiraha H, Takaki A, Iwasaki Y, Kobashi H and Yamamoto K: Prognostic importance of fucosylated alphafetoprotein in hepatocellular carcinoma patients with low alphafetoprotein. J Gastroenterol Hepatol 26(7): 1195-1200, 2011.

9 Kobayashi M, Kuroiwa T, Suda T, Tamura Y, Kawai H, Igarashi M, Fukuhara Y and Aoyagi Y: Fucosylated fraction of alphafetoprotein, L3, as a useful prognostic factor in patients with hepatocellular carcinoma with special reference to low concentrations of serum alpha-fetoprotein. Hepatol Res 37(11): 914-922, 2007.

10 Toyoda H, Kumada T, Tada T, Kaneoka Y, Maeda A, Kanke F and Satomura S: Clinical utility of highly sensitive Lens culinaris agglutinin-reactive alpha-fetoprotein in hepatocellular carcinoma patients with alpha-fetoprotein $<20 \mathrm{ng} / \mathrm{ml}$. Cancer Sci 102(5): 1025-1031, 2011.

11 Imai K, Beppu T, Chikamoto A, Doi K, Okabe H, Hayashi H, Nitta $\mathrm{H}$, Ishiko T, Takamori $\mathrm{H}$ and Baba $\mathrm{H}$ : Comparison between hepatic resection and radiofrequency ablation as first-line treatment for solitary small-sized hepatocellular carcinoma of 3 cm or less. Hepatol Res 43(8): 853-864, 2013.

12 Yamashita Y, Taketomi A, Itoh S, Kitagawa D, Kayashima H, Harimoto N, Tsujita E, Kuroda Y and Maehara Y: Long-term favorable results of limited hepatic resections for patients with hepatocellular carcinoma: 20 years of experience. J Am Coll Surg 205(1): 19-26, 2007.

13 Yamashita Y, Shirabe K, Tsuijita E, Takeishi K, Ikegami T, Yoshizumi T, Soejima Y, Ikeda T, Utsunomiya T and Maehara Y: Third or more repeat hepatectomy for recurrent hepatocellular carcinoma. Surgery 154(5): 1038-1045, 2013.

14 Harimoto N, Shirabe K, Ikegami T, Yoshizumi T, Maeda T, Kajiyama K, Yamanaka $\mathrm{T}$ and Maehara Y: Postoperative complications are predictive of poor prognosis in hepatocellular carcinoma. J Surg Res 199(2): 470-477, 2015.
15 Ryu T, Takami Y, Wada Y, Tateishi M, Matsushima H, Mikagi K and Saitsu H: Double-and triple-positive tumor markers predict early recurrence and poor survival in patients with hepatocellular carcinoma within the Milan criteria and child-pugh class a. J Gastrointest Surg 21(6): 957-966, 2017.

16 Nakagawa S, Hayashi H, Nitta H, Okabe H, Sakamoto K, Higashi T, Kuroki H, Imai K, Hashimoto D, Sakamoto Y, Chikamoto A, Beppu T and Baba H: Scoring system based on tumor markers and Child-Pugh classification for HCC patients who underwent liver resection. Anticancer Res 35(4): 2157$2163,2015$.

17 Takada H, Tsuchiya K, Yasui Y, Nakakuki N, Tamaki N, Suzuki S, Nakanishi H, Itakura J, Takahashi Y, Kurosaki M, Asahina Y, Enomoto N and Izumi N: Irregular vascular pattern by contrastenhanced ultrasonography and high serum Lens culinaris agglutinin-reactive fraction of alpha-fetoprotein level predict poor outcome after successful radiofrequency ablation in patients with early-stage hepatocellular carcinoma. Cancer Med 5(11): 3111-3120, 2016.

18 Cheng J, Wang W, Zhang Y, Liu X, Li M, Wu Z, Liu Z, Lv Y and Wang B: Prognostic role of pre-treatment serum AFP-13\% in hepatocellular carcinoma: Systematic review and metaanalysis. PLoS One 9(1): e87011, 2014.

19 Takayasu K, Arii S, Sakamoto M, Matsuyama Y, Kudo M, Ichida T, Nakashima O, Matsui O, Izumi N, Ku Y, Kokudo $\mathrm{N}$ and Makuuchi M: Clinical implication of hypovascular hepatocellular carcinoma studied in 4,474 patients with solitary tumour equal or less than $3 \mathrm{~cm}$. Liver Int 33(5): 762-770, 2013.

20 Yamashita Y, Tsuijita E, Takeishi K, Fujiwara M, Kira S, Mori M, Aishima S, Taketomi A, Shirabe K, Ishida T and Maehara Y: Predictors for microinvasion of small hepatocellular carcinoma $</=2 \mathrm{~cm}$. Ann Surg Oncol 19(6): 2027-2034, 2012.

21 Fujiyama S, Morishita T, Hashiguchi O and Sato T: Plasma abnormal prothrombin (des-gamma-carboxy prothrombin) as a marker of hepatocellular carcinoma. Cancer 61(8): 1621-1628, 1988.

Received November 7, 2018

Revised December 25, 2018

Accepted December 31, 2018 